\title{
Factors Associated with Caesarean Deliveries in Rural Western Kenya
}

\section{Babu $\mathrm{L}^{1,2 *}$, Onguru $\mathrm{D}^{2}$, Otieno $\mathrm{D}^{2}$,Nyawanda $\mathrm{B}^{1}$ and Otieno $\mathrm{NA}^{1}$ \\ ${ }^{1}$ Kenya Medical Research Institute, Center for Global Health Research, Kisumu, Kenya ${ }^{2} J a r a m o g i$ Oginga Odinga, University of Science and Technology, Kenya}

*Corresponding author: Jaramogi Oginga Odinga, University of Science and Technology, Bondo, Kenya, Tel: +254 707492226/783401454; Email: babulawrence12@gmail.com

\section{Research Article \\ Volume 5 Issue 1}

Received Date: March 29, 2021

Published Date: April 27, 2021

DOI: $10.23880 /$ phoa-16000181

\section{Abstract}

Introduction: Recent investments have shown that Caesarean Section (CS) has been on a steady increase for the past 25 years globally and risk factors associated with CS have been documented, yet there is still little knowledge on the Indications of CS in Siaya County, rural western Kenya. Hence, the aim of this study was to estimate the prevalence of Caesarean section and to identify the risk factors associated with CS delivery among pregnant women in Siaya County, Western Kenya.

Methods: Proportions were used to estimate the prevalence of CS delivery. Multiple logistic regressions were used to determine various exposures for associations with the outcome variable, all exposures with $p$-value $<0.05$ were considered to be independently associated with the caesarean delivery.

Results: This study detected an increase in the trend of caesarean births from 2015 to 2019 with an estimated prevalence of $6.63 \%$. The results from the multivariate analyses indicated that history of hospitalization ${ }_{\mathrm{a}} \mathrm{OR}=2.39 ; 95 \%$ CI $1.45,3.95$; $\mathrm{p}<0.001$ ), previous caesarean section ${ }_{\mathrm{a}} \mathrm{OR}=16.75 ; 95 \% \mathrm{CI} 11.32$, 24.79; $\mathrm{p}<0.001$ ), gestation at Delivery ${ }_{\mathrm{a}} \mathrm{OR}=2.26$; $95 \% \mathrm{CI}$ 1.31-3.89; $\mathrm{p}<0.001$ ) and obesity ${ }_{\mathrm{a}} \mathrm{OR}=2.12 ; 95 \% \mathrm{CI} 0.83-5.43 ; \mathrm{p}=0.12$ ) increased the risk of caesarean delivery.

Conclusion: Previous caesarean, history of hospitalization, gestation age at delivery and obesity were the main reasons leading to caesarean section.

Keywords: Caesarean Section; Delivery; Hospitalization

Abbreviations: CS: Caesarean Section; SVD: Spontaneous Vaginal Delivery; CDC: Centers for Disease Control and Prevention; OR: Odds Ratios; aOR: Adjusted Odds Ratios.

\section{Introduction}

Caesarean section (CS) is a surgical procedure for delivery of the fetus through incisions made in the mother's abdominal and the uterine walls and it is the most common major operation performed in obstetrics [1]. Caesarean section can be a lifesaving operation [2] and commonly preferred measure of delivery when spontaneous vaginal delivery (SVD) would put the life of the mother or the infant at risk. The average global CS rate has increased by $150 \%$ over the past 25 years and is currently at $18.6 \%$ with an average rate of increase of $4.4 \%$ per year [3]. Of the 18.5 million annual estimated CS deliveries, $3.6 \%$ are performed without any medical or surgical indications [4]. In 1985, the 
WHO proposed that CS delivery rates should not exceed 15\% of the total births and stated no additional health benefits above this rate [5]. The lowest global CS rates are found in Africa (7.3\%) and more specifically in Western Africa (3\%) [3]. In line with the global trend, the CS rates in Kenya are generally on the increase [6] with an estimated national CS rate of $9.1 \%$ in 2014 and was projected to reach $16.7 \%$ by 2019 [7]. In 2014, Siaya County contributed about 4.3\% of the national CS rates [7].

A number of factors are likely to be associated with increasing CS including increased access to modern care services, improved economic status of the population, and change in cultural and social factors and supply induced demand for CS [8]. Evidence suggests that mothers living in urban areas are more likely to have current CS delivery than their rural counterparts [9]. Further, mothers having pregnancy risk factors like diabetes and hypertension have also been found to be at higher odds of undergoing CS delivery $[10,11]$. Previous studies have also shown that the risk of maternal mortality, neonatal respiratory morbidity, hysterectomy, ureter and bladder injury, fetal death, placental previa, and uterine rupture in a future pregnancy are increased with CS compared to SVD [12]. Other predictors frequently associated with CS delivery include age, race, primiparity, low stature, high pre-gestational body mass index, antenatal care, excessive gestational weight gain and pregnancy complications [13-17]. County specific data in Kenya have remained sparse and the aforementioned predictors may or may not be applicable to Siaya County. Understanding the prevalence and risk factors associated with caesarean delivery is therefore important as would help the health management teams in designing better interventions to prevent and or reduce caesarean births in Siaya County and similar settings.

\section{Materials and Methods}

\section{Study Site and Population}

This study utilized data collected from the ongoing maternal surveillance study on influenza-associated Illness in Pregnant Women in Western, Kenya (unpublished) being conducted by Kenya Medical Research Institute (KEMRI) in collaboration with the U.S Centers for Disease Control and Prevention (CDC) in Siaya County. This study used data collected from two Ministry of Health facilities in Siaya County; Siaya County Referral Hospital and Bondo subCounty Hospital. Our study targeted pregnant women aged 15-49 years who were residents of Siaya County. Siaya County is an endemic region with high prevalence in Malaria, HIV/ AIDS and respiratory infections [18]. Majority of households in this county have incomes below the poverty line with majority of the people being unemployed [18].

\section{Data and Data Sources}

This study utilized the demographic, obstetric history, medical history, clinical and nutritional variables. The demographic data included age, education level and employment status. We also extracted data on underlying chronic conditions including; HIV status, history of diabetes, pregnancy-induced hypertension, cancer, tuberculosis from the medical history. In addition, gestational age at delivery, first pregnancy, antenatal care visits, and duration of labor, fetal distress, malpresentation, parity and previous CS are among obstetric factors that were investigated in this study. The nutritional variables included maternal weight and height.

\section{Statistical Methods}

Descriptive analyses of the continuous and categorical variables were done by calculating the means and proportions respectively. Chi-square test was used to compare differences in various predictors of interest. Logistic regression models were fitted to determine the relationship between CS deliveries and predictors (including: maternal age, maternal weight, HIV status, education level). Predictors with p-Value $<0.15$ were included in the multivariable logistic regression model. Odds ratios (OR) and adjusted odds ratios (aOR) were reported and all predictors with p-value $<0.05$ were considered to be independently associated with caesarean delivery. We performed statistical analyses using Stata version 15.0 (Stata Corp., College Station, TX).

\section{Ethical Consideration}

This study was approved by the KEMRI -Scientific and Ethical Review Unit (SSC \#2880) and the Institutional Review Board of the U.S Centre for Disease Control and Prevention (CDC) (CDC IRB \#6709). All participants provided written informed consents.

\section{Results}

This study analyzed a total of 3211 records of pregnant mothers who delivered in the two health facilities. The maternal mean age was $26.17( \pm 5.93)$ years with the oldest mother being 41.2 years and youngest being 15.5 years old at enrolment, (Table 1). Majority 1662 (51.8\%) of these mothers were above 25 years old. The adolescent mothers were $372(11.59 \%)$. Most of the women in this study were married $2820(87.8 \%)$ and slightly more than half 1766 $(55.0 \%)$ had primary education. Four hundred and ninetynine $(41.1 \%)$ of the participants were homemakers. Of the total 3211 deliveries, 2998 (93.37\%) were virginal deliveries and $213(6.63 \%)$ were deliveries by caesarean. Of the 213 caesarean deliveries reported, one was a fatality case. 


\begin{tabular}{|c|c|c|c|}
\hline Demographic Variables & $\begin{array}{c}\text { All N=3211 N (\%), } \\
\text { Mean } \pm \text { Sd }\end{array}$ & $\begin{array}{c}\text { Caesarean Section } \\
\mathrm{N}=213, \mathrm{~N}(\%), \text { Mean } \pm \text { S. } D\end{array}$ & $\begin{array}{c}\text { Vaginal Delivery } N=2998, N \\
(\%), \text { Mean } \pm \text { S.D }\end{array}$ \\
\hline Maternal Age & $26.17 \pm 5.93$ & $26.43 \pm 5.07$ & $26.15 \pm 5.98$ \\
\hline \multicolumn{4}{|c|}{ Age Category } \\
\hline$<20$ Years & $372(11.5)$ & $17(8.0)$ & 355 (11.8) \\
\hline 20-24 Years & $1177(36.7)$ & $77(36.2)$ & $1100(36.7)$ \\
\hline$>=25$ Years & $1662(51.8))$ & $119(55.8)$ & $1543(51.5)$ \\
\hline \multicolumn{4}{|c|}{ Marital Status } \\
\hline Single & $371(11.6)$ & $23(10.8)$ & $348(11.6)$ \\
\hline Married & $2820(87.8)$ & $187(87.8)$ & $2633(87.8)$ \\
\hline Widowed & $16(0.5)$ & $2(0.9)$ & $14(0.5)$ \\
\hline Other & $4(0.1)$ & $1(0.5)$ & $3(0.1)$ \\
\hline \multicolumn{4}{|c|}{ Education Level } \\
\hline Never Attended School & $28(0.9)$ & $1(0.5)$ & $27(0.9)$ \\
\hline Primary & $1766(55.0)$ & $92(43.1)$ & $1674(55.8)$ \\
\hline Secondary & $1027(32.0)$ & $70(32.9)$ & 957 (31.9) \\
\hline University & $390(12.1)$ & $50(23.5)$ & $340(11.3)$ \\
\hline \multicolumn{4}{|c|}{ Occupation $(\mathrm{N}=1214)$} \\
\hline Farmer & $83(6.8)$ & $5(5.2)$ & $78(7.0)$ \\
\hline Business Woman & $440(36.2)$ & $40(41.7)$ & $400(35.8)$ \\
\hline Fish Monger & $5(0.4)$ & 0 & $5(0.4)$ \\
\hline Home Maker & $499(41.1)$ & $32(33.3)$ & $467(41.8)$ \\
\hline Employed & $121(10.0)$ & $14(14.6)$ & $107(9.6)$ \\
\hline Other & $66(5.4)$ & $5(5.2)$ & $61(5.4)$ \\
\hline
\end{tabular}

Table 1: Demographic Characteristics of the Study Participants.

S.D Standard deviation

We found that obese mothers (OR=3.25; 95\% CI $1.37,7.73, \mathrm{p}=0.01)$, mothers with gestation age above 41 weeks $(\mathrm{OR}=2.02 ; 95 \% \mathrm{CI} 1.23,3.33, \mathrm{p}=0.01)$, those that had a previous caesarean section (OR=14.20; 95\% CI 9.89, $20.39, \mathrm{p}<0.001$ ) had higher odds of delivering by caesarean section at univariate analysis (Table 2). This was also the case for women who had hospitalization history (OR=1.88; 95\% CI 1.18, 3.00, $\mathrm{p}=0.01$ ) and antepartum hemorrhage complications (OR=7.07; 95\% CI 1.29, 38.96, $\mathrm{p}=0.02$ ). We also found that compared to adolescent mothers, mothers aged between 20-24 years (OR=1.46; 95\% CI 0.85, 2.51, $\mathrm{p}=0.17$ ) and those above 25 years (OR=1.61; 95\% CI 0.96, 2.71, $\mathrm{p}=0.07$ ) had increased risks of caesarean delivery, (Table 3). Also, women who had primary education $(\mathrm{OR}=1.48 ; 95 \% \mathrm{CI}$ $0.20,11.04, \mathrm{p}=0.7)$, secondary (OR=1.97; $95 \% \mathrm{CI} 0.26,14.75$, $\mathrm{p}=0.51$ ) or university education $(\mathrm{OR}=3.97 ; 95 \%$ CI 0.53 , $29.87, \mathrm{p}=0.18)$, those who consumed alcohol $(\mathrm{OR}=1.17 ; 95 \%$ CI $0.15,9.07, \mathrm{p}=0.88$ ) were not associated with caesarean section.

\begin{tabular}{|c|c|c|c|c|}
\hline Predictors & $\begin{array}{c}\text { Caesarean Section N=213, } \\
\text { N(\%) }\end{array}$ & $\begin{array}{c}\text { Vaginal Delivery N=2998, } \\
\text { N (\%) }\end{array}$ & Crude Odds Ratio & P-Value \\
\hline \multicolumn{7}{|c|}{ Age Category } \\
\hline$<20$ Years & $17(8.0)$ & $355(11.8)$ & Ref & \\
\hline $20-24$ Years & $77(36.1)$ & $1100(36.7)$ & $1.46(0.85,2.51)$ & 0.17 \\
\hline$>=25$ Years & $119(55.9)$ & $1543(51.5)$ & $1.61(0.96,2.71)$ & 0.07 \\
\hline \multicolumn{7}{|c|}{ Marital Status } & \multicolumn{3}{|c|}{ Ref } & \\
\hline
\end{tabular}


Public Health Open Access

\begin{tabular}{|c|c|c|c|c|}
\hline Married & $187(87.8)$ & $2633(87.8)$ & $1.07(0.68,1.68)$ & 0.75 \\
\hline Widowed & $2(0.9)$ & $14(0.5)$ & $2.16(0.46,10.09)$ & 0.33 \\
\hline Other & $1(0.5)$ & $3(0.1)$ & $5.04(0.50,50.41)$ & 0.17 \\
\hline \multicolumn{5}{|c|}{ Education Level } \\
\hline Never Attended School & $1(0.5)$ & $27(0.9)$ & Ref & \\
\hline Primary & $92(43.1)$ & $1674(55.8)$ & $1.48(0.20,11.04)$ & 0.7 \\
\hline Secondary & $70(32.9)$ & $957(31.9)$ & $1.97(0.26,14.75)$ & 0.51 \\
\hline University & $50(23.5)$ & $340(11.3)$ & $3.97(0.53,29.87)$ & 0.18 \\
\hline \multicolumn{5}{|c|}{ Occupation } \\
\hline Farmer & $5(5.2)$ & $78(7.0)$ & Ref & \\
\hline Business Woman & $40(41.7)$ & $400(35.8)$ & $1.56(0.60,4.08)$ & 0.36 \\
\hline Fish Monger & 0 & $5(0.4)$ & $\mathrm{N} / \mathrm{A}$ & $\mathrm{N} / \mathrm{A}$ \\
\hline Home Maker & $32(33.3)$ & $467(41.8)$ & $1.07(040,2.83)$ & 0.89 \\
\hline Employed & $14(14.6)$ & $107(9.6)$ & $2.04(0.71,5.90)$ & 0.19 \\
\hline Other & $5(5.2)$ & $61(5.4)$ & $1.28(0.35,4.62)$ & 0.71 \\
\hline Smaller Than Average & $14(6.6)$ & $112(3.7)$ & Ref & \\
\hline Average And Above & $199(93.4)$ & $2886(96.3)$ & $0.55(0.31,1.02)$ & 0.14 \\
\hline \multicolumn{5}{|c|}{ Maternal Nutritional Status } \\
\hline Undernourished & $7(3.3)$ & $124(4.1)$ & Ref & \\
\hline Normal & $110(51.6)$ & $2086(69.6)$ & $0.93(0.43,2.05)$ & 0.87 \\
\hline Overweight & $69(32.4)$ & $641(21.4)$ & $1.91(0.86,4.25)$ & 0.11 \\
\hline Obesity & $27(12.7)$ & $147(4.9)$ & $3.25(1.37,7.73)$ & 0.01 \\
\hline \multicolumn{5}{|c|}{ Size Of The Baby } \\
\hline Smaller Than Average & $12(5.6)$ & $147(4.9)$ & Ref & \\
\hline Average & $200(93.9)$ & $2838(94.7)$ & $0.86(0.47,1.58)$ & 0.63 \\
\hline Larger Than Average & $1(0.5)$ & $13(0.4)$ & $0.94(0.11,7.83)$ & 0.96 \\
\hline HIV Status & $35(16.4)$ & $604(20.2)$ & $0.78(0.53,1.13)$ & 0.19 \\
\hline Diabetes & 0 & $6(0.2)$ & $\mathrm{N} / \mathrm{A}$ & \\
\hline Vaginal Bleeding & $3(1.4)$ & $9(0.3)$ & $0.21(0.06,0.78)$ & 0.02 \\
\hline Other Chronic Complications & $6(2.8)$ & $97(3.24)$ & $0.87(0.38,2.00)$ & 0.74 \\
\hline \multicolumn{5}{|c|}{ Gestational Weeks } \\
\hline$<37$ Weeks & $27(12.7)$ & $452(15.1)$ & Ref & \\
\hline 37-39 Weeks & $86(40.4)$ & $1327(44.3)$ & $1.08(0.70,1.69)$ & 0.72 \\
\hline 40-41 Weeks & $56(26.3)$ & $855(28.5)$ & $1.10(0.68,1.76)$ & 0.7 \\
\hline$>41$ Weeks & $44(20.6)$ & $364(12.1)$ & $2.02(1.23,3.33)$ & 0.01 \\
\hline Fetal Distress & $43(20.19)$ & 0 & $\mathrm{~N} / \mathrm{A}$ & \\
\hline Mal Presentation & $14(6.57)$ & 0 & $\mathrm{~N} / \mathrm{A}$ & \\
\hline Pre-Eclampsia Or Eclampsis & $1(0.5)$ & $10(0.3)$ & $0.71(0.09,5.57)$ & 0.74 \\
\hline $\begin{array}{l}\text { Premature Membrane } \\
\text { Rapture }\end{array}$ & $1(0.1)$ & $1(0.5)$ & $0.07(0.00,1.13))$ & 0.06 \\
\hline \multicolumn{5}{|c|}{ Maternal Parity } \\
\hline Primaparous & $133(62.4)$ & $1513(50.5)$ & Ref & \\
\hline Multiparous & $80(37.6)$ & $1485(49.5)$ & $0.51(0.34,0.77)$ & $<0.001$ \\
\hline
\end{tabular}




\begin{tabular}{|c|c|c|c|c|}
\hline \multicolumn{5}{|c|}{ Gravidity } \\
\hline Primigravida & $60(28.2)$ & $704(23.5)$ & Ref & \\
\hline Multigravida & $153(71.8)$ & $2294(76.5)$ & $0.78(0.57,1.07)$ & 0.12 \\
\hline Prolonged Labour & $58(27.2)$ & 0 & $\mathrm{~N} / \mathrm{A}$ & \\
\hline Previous Caesarean Section & $64(30.1)$ & $88(2.9)$ & $14.20(9.89,20.39)$ & $<0.001$ \\
\hline Antepartum Haemorrhage & $2(0.9)$ & $4(0.1)$ & $7.07(1.29,38.96)$ & 0.02 \\
\hline Smoking & 0 & 0 & $\mathrm{~N} / \mathrm{A}$ & \\
\hline Alcohol & $1(0.5)$ & $12(0.4)$ & $1.17(0.15,9.07)$ & 0.88 \\
\hline \multicolumn{5}{|c|}{ ANC Visits } \\
\hline 1-2 Visits & $209(98.1)$ & $2912(97.1)$ & Ref & \\
\hline $3+$ Visits & $4(1.9)$ & $86(2.9)$ & $0.65(0.24,1.78)$ & 0.4 \\
\hline History Of Hospitalization & $22(10.3)$ & $173(5.8)$ & $1.88(1.18,3.00)$ & 0.01 \\
\hline Maternal Preference & $31(14.6)$ & 0 & $\mathrm{~N} / \mathrm{A}$ & $\mathrm{N} / \mathrm{A}$ \\
\hline
\end{tabular}

Ref-Reference Groups

Table 2: Bivariate analysis: Demographic, socio-economic, medical history, obstetric, clinical and nutritional variables by caesarean section.

\begin{tabular}{|c|c|c|c|}
\hline Predictor Variables & Crude Odds Ratio 95\% CI & aAdjusted Odds Ratio 95\% CI & p-Value \\
\hline \multicolumn{4}{|c|}{ Education level } \\
\hline Never attended school & Ref & & \\
\hline Primary & $1.48(0.20,11.04)$ & $1.13(0.14,8.62)$ & 0.91 \\
\hline Secondary & $1.97(0.26,14.75)$ & $1.20(0.16,9.21)$ & 0.86 \\
\hline University & $3.97(0.53,29.87)$ & $2.06(0.26,16.05)$ & 0.49 \\
\hline \multicolumn{4}{|c|}{ Maternal height (centimetres) } \\
\hline Smaller than average & Ref & & \\
\hline Average and above & $0.55(0.31,1.02)$ & $0.58(0.31,1.09)$ & 0.09 \\
\hline \multicolumn{4}{|c|}{ Maternal nutritional status } \\
\hline Undernourished & Ref & & \\
\hline Normal & $0.93(0.43,2.05)$ & $0.69(0.30,1.59)$ & 0.39 \\
\hline Overweight & $1.91(0.86,4.25)$ & $1.33(0.57,3.13)$ & 0.51 \\
\hline Obesity & $3.25(1.37,7.73)$ & $2.12(0.83,5.43)$ & 0.12 \\
\hline \multicolumn{4}{|c|}{ Gestational weeks } \\
\hline$<37$ weeks & Ref & & \\
\hline 37-39 weeks & $1.08(0.70,1.69)$ & $1.12(0.69,1.83)$ & 0.64 \\
\hline 40-41 weeks & $1.10(0.68,1.76)$ & $1.09(0.65,1.83)$ & 0.74 \\
\hline$>41$ weeks & $2.02(1.23,3.33)$ & $2.26(1.31,3.89)$ & $<0.001$ \\
\hline Vaginal bleeding & $0.21(0.06,0.78)$ & $0.19(0.05,0.82)$ & 0.03 \\
\hline \multicolumn{4}{|c|}{ Maternal parity } \\
\hline Primaparous & Ref & & \\
\hline Multiparous & $0.51(0.34,0.77)$ & $0.53(0.38,0.75)$ & $<0.001$ \\
\hline Previous caesarean section & $14.20(9.89,20.39)$ & $16.75(11.32,24.79)$ & $<0.001$ \\
\hline History of hospitalization & $1.88(1.18,3.00)$ & $2.39(1.45,3.95)$ & $<0.001$ \\
\hline
\end{tabular}

Table 3: Multivariate analysis: Demographic, socio-economic, medical history, obstetric, clinical and nutritional variables associated with caesarean section. 
Multiparity was significantly associated with caesarean delivery though with reduced odds $(\mathrm{OR}=0.51 ; 95 \%$ CI 0.34 , $0.77, \mathrm{p}<0.001)$. Babies born with average weight $(\mathrm{OR}=0.86$; $95 \%$ CI $0.47,1.58, \mathrm{p}=0.63$ ) or larger than average (OR=0.94; $95 \%$ CI $0.11,7.83, \mathrm{p}=0.96)$, HIV positive mothers $(\mathrm{OR}=0.78$; 95\% CI 0.53, 1.13, p=0.19), chronic complications such as Tuberculosis or Asthma (OR=0.87; 95\% CI 0.38, 2.00, $\mathrm{p}=0.74$ ) and multigravida mothers (OR=0.78; 95\% CI 0.57, 1.07, $p=0.12$ ) were not significant predictors of caesarean birth in this study.

Delivery by caesarean was more likely among mothers aged above 41 weeks' gestation ${ }_{\mathrm{a}} \mathrm{OR}=2.26$; $95 \%$ CI 1.31-3.89; $\mathrm{p}<0.001$ ), (Table 3). Mothers who had a previous caesarean section ( ${ }_{a} \mathrm{OR}=16.75$; 95\% CI 11.32, 24.79; $\mathrm{p}<0.001$ ) had higher odds of delivering by caesarean. Likewise, odds of undergoing caesarean section were two times higher among women who were admitted in the hospital during pregnancy due to complications ( ${ }_{\mathrm{a}} \mathrm{OR}=2.39 ; 95 \%$ CI 1.45, 3.95; $\mathrm{p}<0.001$ ).

\section{Discussion}

Our study shows an increase in caesarean deliveries (6.6\%) compared to the 2014 study (4.3\%). We also found that previous caesarean, history of hospitalization and gestation ages at delivery were the leading risk factors for CS in Siaya County. Obesity was strongly associated with caesarean section though the effect was not statistically significant after adjusting for other characteristics. These we find to be in line with the guidelines by $\mathrm{MoH}$, a positive indicator of adherence. However, early ANC attendance and proper care of pregnant women would reduce this rate should factors leading to hospitalizations be cabbed. Further investigation is required to assess the quality of antenatal or obstetric care being provided in the county facilities.

In this study, the overall caesarean section rate was $6.6 \%$ which falls within the World Health Organization's recommended rate of $5 \%$ to $15 \%$ [5]. Caesarean section has been associated with increased risks of negative outcomes though an important intervention to save the lives of mothers and newborns when performed for specific medical and obstetric indications. A number of health benefits of caesarean section have been pointed out including reducing maternal and perinatal mortality [19]. For example, in this study only one maternal death was reported at delivery and this could be enhanced by the adoption of the caesarean section especially in situations where the life of the mother or baby is at risk.

We found that previous caesarean was significantly associated with caesarean delivery such that women who had a previous caesarean were more likely to deliver by caesarean section as compared to those who didn't have a previous section; these findings are consistent with other previous work [20]. Data from other researches have shown that majority of women who had a previous caesarean opted for a repeated caesarean section because of fear of labour pain [21]. Therefore, we believe that increasing the maternal knowledge on ways of relieving labour pain, such as pethidine or epidural anesthesia and providing skilled medical staff to offer quality obstetric services may result in reduced maternal fear of pain and thus encourage more mothers to prefer vaginal delivery to caesarean section [22].

We also found an increased risk of caesarean birth with history of hospitalization. Mothers who presented pregnancy related complications such urinary tract infection, hypertension, vaginal discharge that required hospital admissions were two times more likely to undergo caesarean section than pregnant women who were never admitted to hospital during pregnancy. These findings were similar to some previous studies conducted in Brazil [23]. Their study pointed out influenza infection, urinary tract infection, preterm labour, and hypertensive disorders as the main reasons leading to hospitalization. This observation may be due to long duration of hospitalization which increases depression among pregnant mothers [24]. Depression is associated with high-risk health behaviour such as smoking, poor nutrition, underutilization of prenatal care [25], factors which increases risks of having caesarean delivery. Therefore, pregnant women should be encouraged to seek regular antenatal care which will prevent them from getting hospitalized as of any health or pregnancy complications.

We detected a significant association between gestational age at delivery and caesarean section. We found that women who delivered at 41 weeks' gestation or beyond were two times more likely to deliver by caesarean section as compared to women who delivered at preterm gestation weeks. These findings were also confirmed in other past literature [26,27]. Post term pregnancy is associated with an increased risk of fetal and neonatal mortality and morbidity Olesen, et al. as well as an increased maternal morbidity Caughey et al., In this case, the choice of vaginal delivery would put the mother and infant at risk hence caesarean section may be recommended to be a lifesaving for the mother and infant Lavender, et al. There is a strong body of evidence which demonstrates that induction of labour before 42 weeks of gestation has the potential to prevent the pregnancy complications associated with prolonged pregnancy, for example in the United States, the increase in the incidence of induction of labour was associated with a drop in the number of pregnancies continued beyond 41 and 42 weeks from $18 \%$ in 1998 to $14 \%$ in 2005 [28]. Similarly, the use of early ultrasound for pregnancy dating has been associated with a significant reduction in the incidence of post term pregnancy from $12 \%$ to $3 \%$ Savitz, et al. Therefore, 
we believe that a policy of induction of labour at 41 weeks in post term women and early ultrasound could be beneficial with potential improvement in perinatal outcome and a reduction in maternal complications which will encourage vaginal delivery.

From this study it is demonstrated that obesity was associated with higher odds with caesarean section such that obese mothers were more likely to undergo caesarean delivery as compared to those with normal BMI. These findings are confirmed by previous studies in Africa Onubi, et al. who showed that obese women are $87 \%$ more likely to have caesarean birth than those who are not. Elsewhere in Malawi, Nkoka, et al. confirmed that maternal obesity is associated with increased risk of caesarean birth. Obesity is associated with increased risk of almost all pregnancy complications. Some of the examples include: gestational hypertension, preeclampsia, gestational diabetes mellitus and higher incidence of congenital defects all occur more frequently in obese women than in women with normal BMI. These pregnancy complications as a result of obesity put the mother at a risk of having caesarean delivery. Pregnant women should be educated on nutritional eating behavior during pregnancy to avoid complications caused by obesity.

In this study we found that education was not significantly associated with caesarean delivery though with increased odds such those pregnant women who had primary, secondary or university education were more likely to have caesarean section than those who never attended school. Our results are similar to other studies conducted elsewhere where higher education was significantly associated with lower rates of caesarean section [16]. However, our findings are different from other studies, $[13,15]$ where mothers who had higher education were significantly more likely to have caesarean section as compared to those who did not have a university degree. This insignificance from our results could be explained by the fact that our data was dominated by mothers who had primary education and maybe did not have the knowledge of the benefits that come with caesarean delivery; a planned caesarean section lowers the risks of birth injuries such as asphyxia to the baby and some maternal risk benefits such as avoidance of labour pain.

This study detected a negative association between parity and caesarean section though with significant effects such those multiparous mothers were less likely to go for caesarean delivery as compared to primaparous mothers. This finding was consistent with other researches $[29,30]$. However, these findings are not in line with results presented by Gelaw, et al. who found a positive association between higher parity with caesarean section. They found out higher CS rates in multiparous women as compared to nulliparous women. Studies have shown that primaparous mothers prefer caesarean delivery to vaginal so as to keep their beauty in shape; with caesarean the genital system is kept constant unlike vaginal delivery which causes the form of pelvic and genitalia to change [31]. We believe that with adequate maternal knowledge on the negative risks of caesarean delivery, our young and primaparous mothers will choose vaginal delivery over caesarean section unless it's clinically or medically requested than social reasons such as keeping beauty in shape.

Our findings revealed a negative association between chronic complications and caesarean section. Our results show that women who reported chronic complications such as Tuberculosis or Asthma or HIV infected women were less likely to undergo caesarean delivery than women who did not report such complications. Contrary to our findings, previous studies have shown that women who report chronic health problems (including chronic hypertension, cardiac disease, lung disease or other medical risk factors) are more likely to undergo caesarean section [32,33]. Our observation could be due to low prevalence or unlimited data on noncommunicable diseases among the pregnant women or unlimited access of private facilities data. This calls for better interventions that will investigate medical risk factors both in private and public hospitals to explain the increasing trend of caesarean section.

One of the limitations of this study is that some important variables such as health insurance, physician incentives and exposure to media were not available for this analysis. These are important variables which have been shown to influence CS [34]. We believe availability of such data would have an impact on some predictors in this study thus influencing the results to the near accurate position. Another limitation, our participants were only recruited from public facilities. This limits us to interpret data only in the public hospitals context thus not able to give light on the private health facilities. The availability of private data would have given more insight on the CS coverage in Siaya. In India, it was found that the median CS rate in the private sector was higher (28\%), compared with $5 \%$ in the public sector [35].

\section{Conclusion}

Our findings show that there is an upward trend in the proportion of mothers delivering through CS which together with decline in maternal deaths could point to improved care and equipped delivery facilities showing progress towards the third goal of Sustainable Development Goals which aims to reduce the global maternal mortality ratio to less than 70 per 100,000 live births. From this study, the leading causes of CS were previous caesarean, history of hospitalization, gestation age at delivery and obesity. In order to reduce or avoid unnecessary CS from occurring, it is suggested that 
better antenatal services be provided to reduce number of hospitalized cases due to health or pregnancy complicated issues or unhealthy eating behaviors. Appropriate training of hospital stuff with skills is important to offer careful and justified trial of labour to reduce repeated CS. Further studies with robust methodology are needed to investigate on the quality of antenatal or obstetric care being provided and to accept or disagree with the current findings.

\section{Acknowledgement}

The authors are grateful to KEMRI/CDC field staff who participated in data collection and skilled obstetricians who ensured safety delivery to our mothers. Also, we are thankful to Dr Nancy Otieno for granting the permission to use the datasets to answer the study objectives. This paper is published with the approval of the Director of Kenya Medical Research Institute.

\section{Author Contributions}

This study was proposed by L.B and all contributed to study materials and methods. L.B analyzed the data and B.N helped in the interpretation of the results. L.B drafted the manuscript under the supervision of D.0, D.O. Finally, all authors reviewed the manuscript for formatting, grammar and novelty before the submission of the final manuscript.

\section{Conflicts of Interest}

The authors declared no interest of conflicts.

\section{References}

1. Yadav S, Kaur S, Yadav SS, Thakur B (2016) Analysis of cesarean rate, indications and complications: review from medical college Ambala, Haryana, India. Int J Reprod Contracept Obstet Gynecol 5(10): 3326-3329.

2. Lavender T, Hofmeyr GJ, Neilson JP, Kingdon C, Gyte GML (2012) Caesarean section for non-medical reasons at term. Cochrane database Sys Rev (3): CD004660.

3. Betran AP, Ye J, Moller AB, Zhang J, Gulmezoglu AM, et al. (2016) The increasing trend in caesarean section rates: global, regional and national estimates: 1990-2014. PLoS One 11(2): e0148343.

4. Walana W, Acquah EK, Ziem JB, Vicar EK, Acquah SEK, et al. (2017) Preference of Birth Delivery Modes among Women Attending Antenatal and Postnatal Clinics in the Tamale Metropolis of Ghana. J Preg Child Health 4: 297.

5. WHO (1985) Appropriate technology for birth. Lancet 2(8452): 436-437.
6. Lauer JA, Betran AP, Merialdi M, Wojdyla D (2010) Determinants of caesarean section rates in developed countries: supply, demand and opportunities for control. World health report 29: 1-22.

7. (2014) Assistence during delivery. KDHS.

8. Haider MR, Rahman MM, Moinuddin Md, Rahman AE, Ahmed S, et al. (2018) Ever-increasing Caesarean section and its economic burden in Bangladesh. PLoS One 13(12): e0208623.

9. Stanton CK, Holtz SA (2006) Levels and trends in cesarean birth in the developing world. Stud Fam Plann 37(1): 41-48.

10. Karim F, Ghazi A, Ali T, Aslam R, Afreen U, et al. (2011) Trends and determinants of caesarean section. Journal of Surgery Pakistan (International) 16(1): 22-27.

11. Abdelraheim AR, Gomaa K, Ibrahim EM, Mohammed MM, Khalifa EM, et al. (2019) Intra-abdominal infection (IAI) following cesarean section: a retrospective study in a tertiary referral hospital in Egypt. BMC Pregnancy Childbirth 19(1): 234.

12. Belizan JM, Althabe F, Cafferata ML (2007) Health consequences of the increasing caesarean section rates. Epidemiology 18(4): 485-486.

13. Klemetti R, Che X, Gao Y, Raven J, Wu Z, et al. (2010) Cesarean section delivery among primiparous women in rural China: an emerging epidemic. Am J Obstet Gynecol 202(1): 65.e1-6.

14. Kac G, Silveira EA, Oliveira LC, Araujo DMR, Sousa EB (2007) Fatores associados a ocorrência de cesarea e aborto em mulheres selecionadas em um centro de saude no municipio do Rio de Janeiro, Brasil. Revista Brasileira de Saude Materno Infantil 7(3): 271-280.

15. Hezarjarib J, Abbaspoor A (2010) Influence socialeconomic on women fertility rate. Social Research 3: 178-184.

16. Konlan DK, Baku EK, Japiong M, Konlan KD, Amoah RM (2019) Reasons for women's choice of elective caesarian section in duayaw nkwanta hospital. Journal of Pregnancy, pp: 7.

17. Cesaroni G, Forastiere F, Perucci CA (2008) Are cesarean deliveries more likely for poorly educated parents? A brief report from Italy. Birth 35(3): 241-244.

18. Amek N, Vounatsou P, Obonyo B, Hamel M, Odhiambo F, et al. (2015) Using health and demographic surveillance system (HDSS) data to analyze geographical distribution 
of socio-economic status; an experience from KEMRI/ CDC HDSS. Acta Trop 144: 24-30.

19. Boerma T, Ronsmans C, Melesse DY, Barros AJD, Barros FC, et al. (2018) Global epidemiology of use of and disparities in caesarean sections. The Lancet 392(10155): 1341-1348.

20. Young CB, Liu S, Muraca GM, Sabr Y, Pressey T, et al. (2018) Mode of delivery after a previous cesarean birth, and associated maternal and neonatal morbidity. CMAJ 190(18): E556-E564.

21. Sindiani A, Rawashdeh H, Obeidat N, Zayed F, Alhowaryb AA (2020) Factors that influenced pregnant women with one previous caesarean section regarding their mode of delivery. Ann Med Surg 55: 124-130.

22. Hawkins JL, Arens JF, Bucklin BA, Caplan RA, Chestnut $\mathrm{DH}$, et al. (1999) Practice Guidelines for Obstetrical Anesthesia A Report by the American Society of Anesthesiologists Task Force on Obstetrical Anesthesia: Task Force on Obstetrical Anesthesia. Obstetric Anesthesia Digest 19(2): 67.

23. Falavina LP, Oliveira RR, Melo EC, Varela PLR, Mathias TAF (2018) Hospitalization during pregnancy according to childbirth financial coverage: a population-based study. Rev Esc Enferm USP 52: e03317.

24. Kitagawa R, Furukori NY, Tsushima T, Kaneko S, Fukuda I (2011) Depression increases the length of hospitalization for patients undergoing thoracic surgery: a preliminary study. Psychosomatics 52(5): 428-432.

25. Marcus SM, Flynn HA (2008) Depression, antidepressant medication, and functioning outcomes among pregnant women. Int J Gynaecol Obstet 100(3): 248-251.

26. Treger M, Hallak M, Silberstein T, Friger M, Katz M, et al. (2002) Post-term pregnancy: should induction of labor be considered before 42 weeks? J Matern Fetal Neonatal Med 11(1): 50-53.

27. Alexander JM, MCIntire DD, Leveno KJ (2001) Prolonged pregnancy: induction of labor and cesarean births. Obstet Gynecol 97(6): 911-915.

28. Martin JA, Hamilton BE, Sutton PD, Ventura SJ, Menacker F, et al. (2007) Births: final data for 2005. Natl Vital Stat Rep 56(6): 100-103.

29. Zakerihamidi M, Roudsari RL, Khoei EM (2015) Vaginal delivery vs. cesarean section: A focused ethnographic study of women's perceptions in The North of Iran. Int J Community Based Nurs Midwifery 3(1): 39-50.

30. Gama SGN, Viellas EF, Schilithz AOC, Filha MMT, Carvalho ML, et al. (2014) Factors associated with caesarean section among primiparous adolescents in Brazil, 20112012. Cad Saude Publica 30(S1): S1-S11.

31. Khatony A, Soroush A, Andayeshgar B, Saedpanah N, Abdi A (2019) Attitude of primiparous women towards their preference for delivery method: a qualitative content analysis. Archives of Public Health 77(38): 1-9

32. Neuman M, Alcock G, Azad K, Kuddus A, Osrin D, et al. (2014) Prevalence and determinants of caesarean section in private and public health facilities in underserved South Asian communities: cross-sectional analysis of data from Bangladesh, India and Nepal. BMJ open 4(12): e005982.

33. Amjad A, Amjad U, Zakar R, Usman A, Zakar MZ, et al., (2018) Factors associated with caesarean deliveries among child-bearing women in Pakistan: secondary analysis of data from the demographic and health survey, 2012-13. BMC Pregnancy and Childbirth 18(1): 113.

34. Anwar I, Sami M, Akhtar N, Chowdhury ME, Salma U, et al. (2008) Inequity in maternal health-care services: evidence from home-based skilled-birth-attendant programmes in Bangladesh. Bull World Health Organ 86(4): 252-259.

35. Ghosh S (2010) Increasing trend in caesarean section delivery in India: Role of medicalisation of maternal health. Institute for Social and Economic Change Bangalore. 